\title{
Personal Protection Equipment and Emergency Surgery during the COVID-19 Pandemic in Spain
}

\author{
Carlos Yánez Benítez ${ }^{1}$, José Fernando ${ }^{2}$, Antonio Güemes ${ }^{3}$, José Aranda ${ }^{4}$, Fernando Turégano ${ }^{5}$, Luca Ponchietti ${ }^{6}$, \\ Felipe Pareja ${ }^{7}$, Virginia Durán ${ }^{8}$, Juan L Blas ${ }^{9}$
}

\begin{abstract}
Introduction: In December 2019, in Wuhan, China, a new viral disease, COVID-19, was diagnosed, and in January 2020, the first case was diagnosed in Spain. In April, Spain had reported more than 200,000 cases, 38,000 of which were health workers, representing more than 16\% of the volume of contagion in the general population. The objective of our study was to determine the availability, characteristics of use, and the need for improvisation of personal protective equipment (PPE) during the first wave of the COVID-19 pandemic in Spain.

Materials and methods: An online, anonymous, prospective survey was carried out from April 2 to 15 by an e-mail invitation to 562 of the Trauma and Emergency Surgery sections of the Spanish Association of Surgeons. The survey collected demographic data, the region of clinical practice, patterns of PPE use in emergency surgeries, and the improvisation of equipment.

Results: Total 58 health workers from 12 communities completed the survey, 95\% surgeons. Total 28\% received training with PPE during the pandemic, and $44 \%$ rated it as insufficient. The PPE used in surgery were double glove (74\%), face shield (72\%), surgical glasses (67\%), waterproof gown (67\%), and boot covers (32\%). Lack of N95/FPP2/3 was reported by $82 \%$ and other elements of PPE by $68 \%$. More than half of the respondents (51\%) improvised PPE.

Conclusion: The results reflect a low degree of training on PPE use before and during the first wave of the pandemic, the lack of PPE, especially masks, and the need to use nonapproved material as a protection mechanism.
\end{abstract}

Keywords: COVID-19, Pandemic, Personal protective equipment, Survey study.

\section{RESUMEN}

Introducción: En diciembre de 2019, en Wuhan, China, se diagnosticó una nueva enfermedad viral, COVID-19, y en enero de 2020, el primer caso fue diagnosticado en España. En abril, España había notificado más de 200.000 casos, 38.000 de los cuales eran trabajadores sanitarios, lo que representa más del $16 \%$ del volumen de contagio en la población general. El objetivo de nuestro estudio fue determinar la disponibilidad, características de uso y la necesidad de improvisación de equipos de protección personal (EPI) durante la primera ola de la pandemia COVID19 en España.

Materiales y métodos: Entre el 2 y el 15 de abril se realizó una encuesta prospectiva, anónima y en línea mediante invitación por correo electrónico a 562 Secciones de Traumatología y Cirugía de Urgencias de la Asociación Española de Cirujanos. La encuesta recopiló datos demográficos, la región de clínica práctica, patrones de uso de EPP en cirugías de emergencia y la improvisación de equipos.

Resultados: Un total de 58 trabajadores de la salud de 12 comunidades completaron la encuesta, 95\% cirujanos. Total 28\% recibió capacitación con EPP durante la pandemia, y el $44 \%$ la calificó como insuficiente. Los EPI utilizados en cirugía fueron doble guante (74\%), careta (72\%), gafas quirúrgicas (67\%), bata impermeable (67\%) y cubrebotas (32\%). El 82\% informó de la falta de N95 / FPP2 / 3 y el $68 \%$ de otros elementos del EPP. Más de la mitad de los encuestados (51\%) improvisó EPP.

Conclusión: Los resultados reflejan un bajo grado de capacitación sobre el uso de EPP antes y durante la primera ola de la pandemia, la falta de EPP, especialmente máscaras y la necesidad de utilizar material no aprobado como mecanismo de protección.

Palabras clave: COVID-19, Pandemia, Equipo de protección personal, Estudio de encuesta.

Panamerican Journal of Trauma, Critical Care \& Emergency Surgery (2020): 10.5005/jp-journals-10030-1292

\section{INTRODUCTION}

In December 2019, in Wuhan, China, several cases of severe acute respiratory syndrome due to coronavirus-2 (SARS-CoV-2) were diagnosed. This novel disease was called coronavirus disease-2019 (COVID-19). ${ }^{1}$ Due to the lack of control of the initial outbreak and our society's current ability to use mass means of air transport, the virus's rapid global spread occurred. In March, the World Health Organization (WHO) declared the COVID-19 pandemic. ${ }^{2}$ As of the first quarter of 2020, the whole world witnessed an escalation in the number of infected, leading the health systems of many countries to collapse, and to a shortage of personal protective equipment (PPE). By May 17, the WHO reported more than 4,400,000 confirmed cases

\footnotetext{
1,2,9 General Surgery Department, Hospital Royo Villanova, Zaragoza, Spain

${ }^{3}$ General Surgery Department, Lozano Blesa University Hospital, Zaragoza, Spain

${ }^{4}$ General Surgery Department, Regional University Hospital, Málaga, Spain

${ }^{5}$ General Surgery Department, Emergency Surgery Section, Hospital Gregorio Marañón, Madrid, Spain

${ }^{6}$ General Surgery Department, Hospital San Jorge, Huesca, Spain

${ }^{7,8}$ General Surgery Department, Virgen del Rocío Hospital, Seville, Spain
}

(c) The Author(s). 2020 Open Access This article is distributed under the terms of the Creative Commons Attribution 4.0 International License (https://creativecommons. org/licenses/by-nc/4.0/), which permits unrestricted use, distribution, and non-commercial reproduction in any medium, provided you give appropriate credit to the original author(s) and the source, provide a link to the Creative Commons license, and indicate if changes were made. The Creative Commons Public Domain Dedication waiver (http://creativecommons.org/publicdomain/zero/1.0/) applies to the data made available in this article, unless otherwise stated. 
worldwide, more than 180,000 of them in Europe, and Spain as the fourth country in the world with 230,183 cases reported. The global death toll by then had already exceeded $305,000{ }^{3}$ The number of infected health sector professionals increased alarmingly, and in a statement dated April 30, 2020, the Spanish Collegiate Medical Organization requested the Minister of Health and the Minister of Labor that the medical profession has declared a risk because at that date the number of health professionals infected in Spain exceeded 38,000 , which represented more than $16 \%$ of the volume of contagion in the general population. ${ }^{4}$

The high number of infected health personnel brought the focus of attention to the availability of PPE, its quality, and the protocols for its use, including the necessary training for its proper use. The high demand generated by the pandemic caused problems in the production and distribution of such products. On February 27 , the WHO issued a statement with recommendations for their use during the pandemic, contemplating measures to optimize their availability and rationale. ${ }^{5}$ Given the high rate of infection among healthcare personnel, and knowing that such equipment is essential to prevent infection in emergency surgeons, the trauma and emergency surgery section (STCU) of the Spanish association of surgeons (AEC) carried out a study to determine PPE availability, their characteristics, use habits and frequency, as well as ways to improvise them, if needed, anticipating an insufficiency scenario while the COVID-19 set place on Spanish soil.

\section{Materials and Methods}

The survey collected demographic data, measures adopted in the hospital where the respondents worked, and patterns of PPE use within the survey period. The demographic information requested age, gender, title, and location. It also asked about the preventive measures adopted, including PPE use training, placement and removal protocols, the existence of specific areas for donning and doffing, availability of such equipment, their utilization when performing their emergency surgery, and if there was a need to improvise in their absence. Questions were made about the presence of confirmed or suspected infected patients in their hospital and service and whether they had performed surgical procedures on COVID-19 patients to date. Finally, the participants were asked if they had been tested for COVID-19, either after having intervened infected patients or during the pandemic period as of the survey's closing date. The data collected for the different variables were analyzed using descriptive statistics, calculating frequencies, and percentages.

\section{Results}

A total of 58 (10\%) of the professionals invited completed the survey, 32 (55\%) men and 26 (45\%) women, the majority (57\%) between 31 and 45 years old. The vast majority (95\%) were surgeons and a few surgical residents (3\%) and emergency physicians (2\%). The answers received were from 12 of the 17 autonomous communities, with the most significant number coming from Aragón (13), Andalucía (11), Madrid (9), and Catalonia (8), representing 22, 19, 16, and 14\%, respectively (Fig. 1). Most respondents (83\%) joined the COVID reaction committee of their affiliated hospitals. Development of work protocols and facilities adaptation was reported by $71 \%$, organization of specific operating rooms for COVID-19 cases by $86 \%$, and a similar figure admitted patients to their services. Open surgery on suspected or confirmed cases was reported by $43 \%$
Corresponding Author: Carlos Yánez Benitez, General Surgery Department, Hospital Royo Villanova, Zaragoza, Spain, Phone: +34976466910, e-mail: carlosyb1@gmail.com

How to cite this article: Yánez Benítez C, Fernando J, Güemes A, et al. Personal Protection Equipment and Emergency Surgery during the COVID-19 Pandemic in Spain. Panam J Trauma Crit Care Emerg Surg 2020;9(3):181-185.

Source of support: Nil

Conflict of interest: None

and laparoscopic procedures by $39 \%$. Only $17 \%$ informed to have commercial systems installed to filter the pneumoperitoneum, which pushed $59 \%$ of them to improvise an alternative filtration equipment.

With COVID-19 patients admitted to the service, $86 \%$ wore surgical masks when passing the plant, and only $24 \%$ used N95/ FPP2/3. More than half reported not having received training on PPE use before the infected numbers spiked, and a third of those who did rate it as insufficient. When the admission of new victims of the virus increased significantly, more than a third of the survey respondents continued without training. At the same time, the perception of insufficiency rose to $45 \%$. However, a visible checklist when donning the equipment was reported by $61 \%$, and two-thirds used peer support to check appropriate protection. They also reported the existence of a checklist to be used when removing protective equipment (61\%), visible in the same area where they were brought in, specially designated for both operations (60\%).

Seventy-two percent of respondents routinely performed seal tests on the N95/FPP2/3 mask upon donning. Among those with a beard, $40 \%$ had difficulty adjusting it over the nose or under the chin, so half of them needed to shave to improve the fit. The elements of PPE used routinely during the surgery reported were a double glove, face shield, surgical glasses, waterproof gown, and boot covers (Fig. 2). However, only $40 \%$ claimed to use all the listed components. When asked if they experienced a lack of PPE elements and specifically FPP2/3/N95 masks, the vast majority answered affirmatively that more than half needed to reuse it. The vast majority were forced to wear it throughout the watch (Fig. 3). The provision of various protection elements was reported

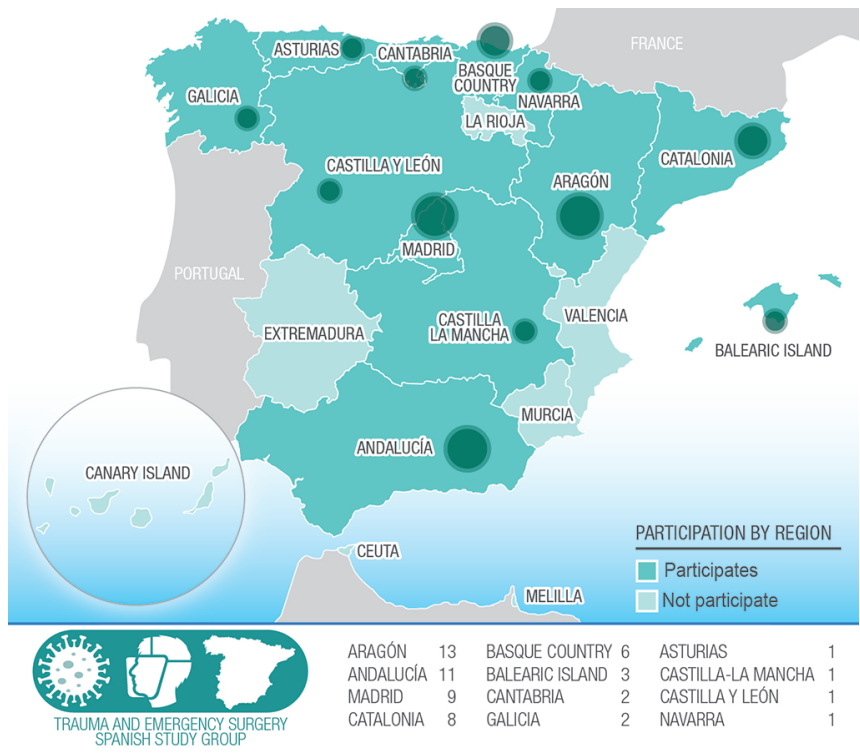

Fig. 1: Spanish map showing the responses and participation in the study 


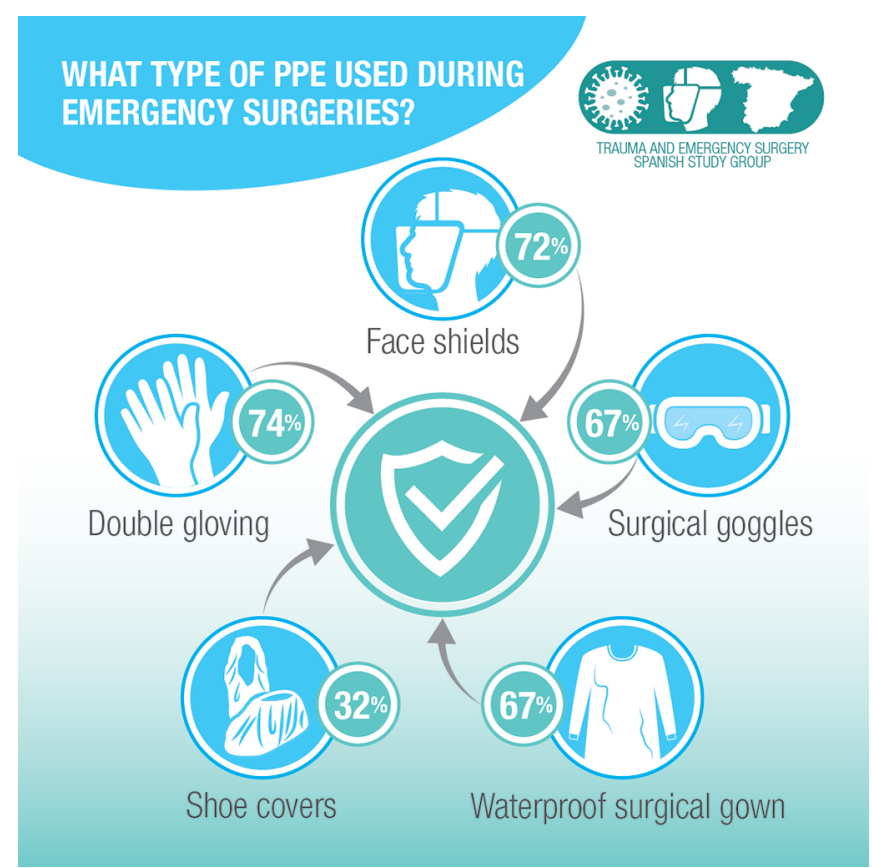

Fig. 2: Elements of PPE used routinely during emergency surgery in Spain during the first wave of COVID-19

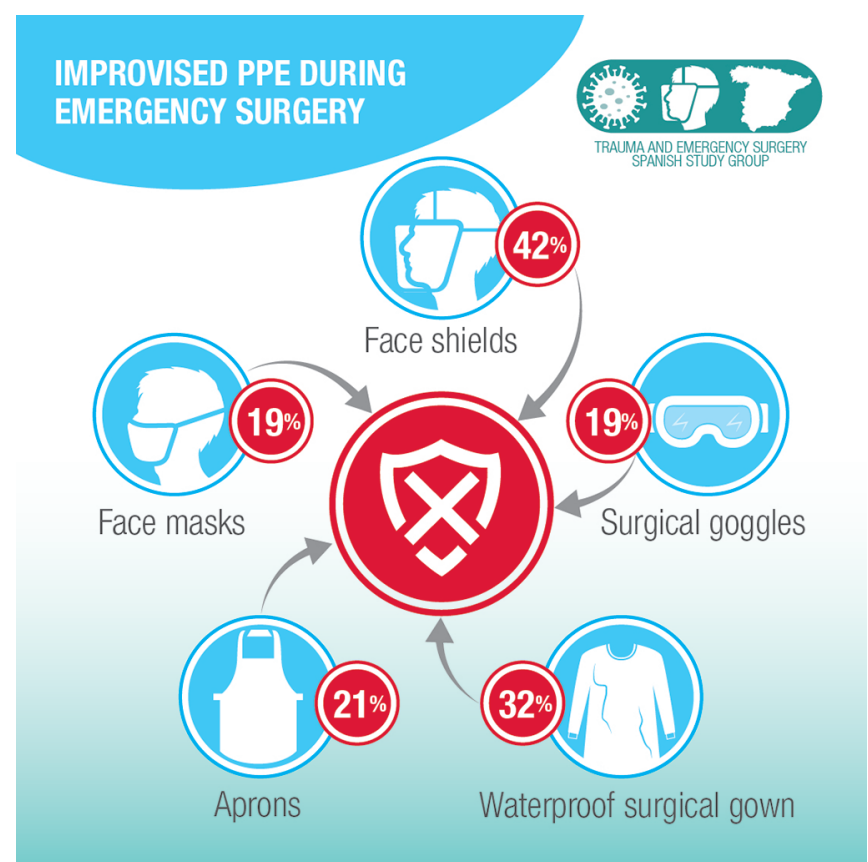

Fig. 4: Use of improvised equipment while performing emergency surgery

as insufficient, for which more than half had to use unapproved and improvised equipment (Fig. 4). Almost half (46\%) of the study participants did not feel protected by wearing PPE during emergency surgery. Even though $33 \%$ of the study participants had symptoms suggestive of COVID-19 by the date of the study, only $19 \%$ had undergone some diagnostic test after performing surgery in COVID-19 patients, and only one-quarter of the participants (26\%) experienced some screening test for the disease during the period of the study.

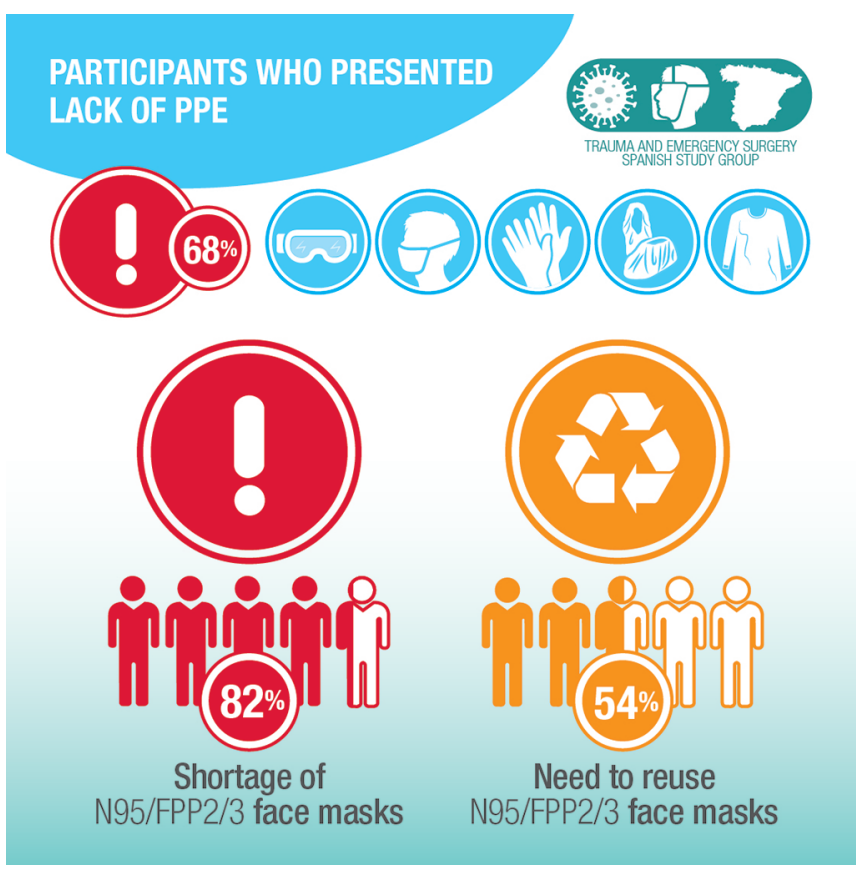

Fig. 3: Lack of PPE elements and specifically N95/FPP2/3 masks during the studied period

\section{Discussion}

Our study portrayed the use of PPE by emergency surgeons for a short period, while the highest record of SARS-CoV-2 infections in Spain was achieved: the first 15 days of April 2020. By the date the survey was carried out, the country registered 6,055 confirmed cases per day. ${ }^{3}$ The national health system was at the limit of its capacities. The health personnel were over-required, which could partly explain the low participation level in the survey, $10 \%$ of the invitations sent. The other aspect that could influence was the overload of information circulating through multiple media about the new disease. The participants' geographical distribution was heterogeneous, with higher participation by surgeons from Aragón, Andalucía, Madrid, and Catalonia. The lack of surgeons' involvement from the Valencian Community, La Rioja, Extremadura, and the Canary Islands, from which no response was obtained, is striking. Despite the care overload that was experienced on those dates, it is essential to highlight the commitment and leadership of surgeons during the pandemic. In our study, the vast majority of participants (83\%) were integrated into the COVID response committees of their respective hospitals, contributing to the preparation and adoption of measures to guarantee their services' continuity. It is interesting to note that at the time of conducting the survey, the vast majority of respondents already had the operating room set up to operate on COVID-19 patients; this finding highlights the effort and organizational capacity of the study's services. The AEC supported this commitment assumed at the individual level in each hospital by developing and publication of clinical practice guidelines and consensus documents available on the association's website. ${ }^{6}$

The results of the survey show that training for the use of PPE before and during the pandemic was deficient: less than half (47\%) before the pandemic and even more deficient during its development, where only $28 \%$ received training and the training received was rated as insufficient by about half (44\%). Several factors have been able to justify this phenomenon: the overload 
of care, the rapid increase in the number of cases, and the shortage of material available for training. This finding has been previously studied by Amerita et al. who reported in a study of 222 health workers that many do not receive formal training to use this equipment, and those who do receive it qualify it as suboptimal and lacking criteria demonstrating efficacy. ${ }^{7,8}$ We consider that this lack of preparation could have contributed to the high infection figures of health personnel registered at the national level. A positive aspect that contrasts with these results is that more than half had a specific area and a protocol for donning and doffing protective equipment. This measure is essential to minimize the risk of infection, especially while removing the contaminated equipment. ${ }^{9}$ One of the techniques described to minimize the risk during placement and removal of the equipment is placement and verification of the technique by a colleague, ${ }^{10,11}$ which was applied by more than two-thirds of the participants.

Another fundamental aspect of minimizing the risk of infection by SARS-CoV-2 is the proper selection and use of the mask. Although checking the appropriate seal of the N95/FPP2/3 masks is essential, a third of the participants did not perform it. To ensure proper protection, the mask must offer an adequate seal to the facial contour, and there must be no space for the entry of infectious agents between these two surfaces. For this reason, it is essential to check when placing it. ${ }^{12,13}$ This aspect of its use deserves to be highlighted in male healthcare personnel with beards since wearing it can create an obstacle to proper sealing. Our survey revealed that half of the population studied who wore a beard required shaving to facilitate the mask's sealing. Facial hair poses a problem for the fit of N95/FPP2/3 masks, which is why some authors and the centers for disease control and prevention (CDC) even recommend using powered air-purifying respirators (PAPRs) equipment for healthcare personnel with beards. The PAPR does not require a tight seal to the face and can offer a level of protection even higher than the N95/ FPP2/3 masks. ${ }^{14}$ Sandaradura et al. report that, in a population of 105 male healthcare personnel, none with beards could pass the seal tests for N95/FPP2/3 masks. ${ }^{15}$ Despite shaving and the absence of facial hair, an adequate seal is not always achieved with the N95/ FPP2/3 masks, so it is essential to carry out sealing and adjustment tests by each center's occupational medicine service. ${ }^{16,17}$ Another relevant aspect of our study was the high degree of scarcity of said components of the protective equipment, which led to the need to use them for periods longer than those for which they are designed. Some publications warn about the risk of contagion when used in such conditions. ${ }^{18}$ Although this finding has also been described in other studies during the pandemic, the magnitude of the shortage of masks reported by the participants in our study (greater than $80 \%$ ) and other components of the PPE, greater than $51 \%$, is striking. When comparing our results with those obtained by the survey carried out by the Royal College of Surgeons of 1,200 NHS surgeons in the United Kingdom during the pandemic, there is a significant difference, since they reported that $30.5 \%$ experienced a lack of N95/FPP2/3 masks and $32.8 \%$ valued the provision of PPE as insufficient. ${ }^{19}$

Our survey also reflected the need to use unapproved and sometimes improvised equipment. Several recently published works report experiences with the improvisation of PPE using $3 \mathrm{D}$ printers, with which they have developed everything from N95/FPP2/3 masks to face shields, using composite polyamide components. ${ }^{20}$ Although such solutions in times of deficiency are undeniable extreme, they do not always offer adequate protection because they are not approved and tested to guarantee their effectiveness. Another important aspect is the feeling of confidence and security that this makeshift equipment offers to the surgeon. Our study shows that almost half did not feel protected wearing PPE and having to use nonapproved or reused material could contribute to that feeling of lack of adequate protection. Improvised PPE can favor health personnel's contagion since they can provide a false sense of security, although they do not provide sufficient protection. The National Commission for Health of China reported 3,300 infected health workers and at least 22 deaths. The figures for Italy are approximately $20 \%$ of the health personnel involved in treating these patients. ${ }^{21}$ In Spain, the number of health personnel infected has been very high. However, the number of infected is challenging to determine considering the low level of tests performed during the study period and the lack of updated publication by official sources.

Our study presented several limitations: the level of responses was low and the absence of these from a quarter of the autonomous communities. The study's duration was limited to the pandemic's initial period when the infected curve was at its highest. We understand that the study design may have been influenced by the degree of motivation and the experience lived by the designers. Despite the limitations, we consider the results obtained very useful, mainly when considering that it highlights the need to guarantee PPE in sufficient quantity and quality. It also highlights the obligation to develop PPE donning and doffing training programs and proven mask sealing programs, especially if we consider the possibility of a second wave of infections in the fall.

\section{Ethical Standards}

This article does not contain any studies involving human or animal participants performed by any of the authors.

\section{ACKNOWLedgments}

The authors thank Mercedes Muñoz, for her cooperation in the bibliographic search; Carlos Yánez, PhD, for reviewing the text; and Ilaria Bondi, medical illustrator.

\section{References}

1. Lu H, Stratton CW, Tang Y. Outbreak of pneumonia of unknown etiology in Wuhan China: the mystery and the miracle. J Med Virol 2020;92(4):401-402. DOI: 10.1002/jmv.25678.

2. World Health Organization. WHO Director-General's opening remarks at the media briefing on COVID-19- 11 March 2020 https://www.who. int/dg/speeches/detail/who-director-general-s-opening-remarks-atthe-media-briefing-on-covid-19-11-March-2020 [accessed 17 May 2020].

3. WHO. Novel coronavirus (COVID-19) situation. Updated May 17, 2020 https://covid19.who.int [accessed May 17, 2020].

4. Statement from the Spanish College Medical Organization. April 30, 2020. https://www.cgcom.es/sites/default/files//u183/ np_solicitud_profesion_de_riesgo_a_ministros_de_sanidad_y_ trabajo_30_04_2020.pdf [accessed May 17, 2020].

5. Rational use of personal protective equipment for coronavirus disease 2019 (COVID-19). Interim guidance February 27, 2020. https:// apps.who.int/iris/bitstream/handle/10665/331215/WHO-2019-nCovIPCPPE_use-2020.1-eng.pdf [accessed May 17, 2020].

6. Balibrea JM, Badia JM, Rubio I, et al. Surgical management of patients with COVID-19 infection. recommendations of the spanish association of surgeons. Cir Esp 2020;98(5):251-259. DOI: 10.1016/j. ciresp.2020.03.001. 
7. Guo YP, Li Y, Wong PL. Environment and body contamination: a comparison of two different removal methods in three types of personal protective clothing. Am J Infect Control 2014;42(4):e39-e45. DOI: 10.1016/j.ajic.2013.12.021.

8. John A, Tomas ME, Cadnum JL, et al. Are health care personnel trained in correct use of personal protective equipment? Am J Infect Control 2016;44(7):840-842. DOI: 10.1016/j.ajic.2016.03.031.

9. Phan LT, Maita D, Mortiz DC, et al. Personal protective equipment doffing practices of healthcare workers. J Occup Environ Hyg 2019;16(8):575-581. DOI: 10.1080/15459624.2019.1628350.

10. Andonian J, Kazi S, Therkorn J, et al. Effect of an intervention package and teamwork training to prevent healthcare personnel self-contamination during personal protective equipment doffing. clin infect dis. 2019;69(Suppl 3):S248-S255. DOI: 10.1093/cid/ciz618.

11. Suen LKP, Guo YP, Tong DWK, et al. Self-contamination during doffing of personal protective equipment by healthcare workers to prevent Ebola transmission. Antimicrob Resist Infect Control 2018;7:157. DOI: 10.1186/s13756-018-0433-y.

12. Oberg T, Brosseau LM. Surgical mask filter and fit performance. Am J Infect Control 2008;36(4):276-282. DOI: 10.1016/j.ajic.2007.07.008.

13. Holland M, Zaloga DJ, Friderici CS. COVID-19 personal protective equipment (PPE) for the emergency physician. Vis J Emerg Med 2020;19:100740. DOI: 10.1016/j.visj.2020.100740.

14. Considerations for Optimizing the Supply of Powered Air-Purifying Respirators (PAPRs) https://www.cdc.gov/coronavirus/2019-ncov/ hcp/ppe-strategy/powered-air-purifying-respirators-strategy.html. [accessed 05/28/2020].

15. Sandaradura I, Goeman E, Pontivivo G, et al. A close shave? performance of $\mathrm{P} 2 / \mathrm{N} 95$ respirators in healthcare workers with facial hair: results of the BEARDS (benchmarking adequate respiratory defenses) study. J Hosp Infect 2020;104(4):529-533. DOI: doi. org/10.1016/j.jhin.2020.01.006.

16. Jaillette $E$, Girault $C$, Brunin $G$, et al. French intensive care society, international congress - réanimation 2016. Ann Intensive Care 2016;6(Suppl 1):50. DOI: 10.1186/s13613-016-0114-z.

17. Chughtai AA, Seale H, Islam MS, et al. Policies on the use of respiratory protection for hospital health workers to protect from coronavirus disease (COVID-19). Int J Nurs Stud 2020;105:103567. DOI: 10.1016/j. ijnurstu.2020.103567.

18. Hadi S. Covid-19: exposing frontline NHS staff to dangers by asking them to reuse PPE. BMJ 2020;369:m1911. DOI: 10.1136/bmj.m1911.

19. Survey findings: PPE and testing during the COVID-19 pandemic. https://www.rcseng.ac.uk/coronavirus/survey-findings-ppe/ [accessed May 27, 2020].

20. Swennen G, Pottel L, Haers P. Custom-made 3D-printed face masks in case of pandemic crisis situations with a lack of commercially available FFP2/3 masks. Int J Oral Maxillofac Surg 2020;49(5):673-677. DOI: 10.1016/j.ijom.2020.03.015.

21. COVID-19: protecting health-care workers. Lancet 2020;395:922. DOI: 10.1016/S0140-6736(20)30644-9. 